\title{
Snails, Teeth and New Space
}

Although it is very pretty, the picture on the front page is not only there for that reason. It shows the mother-ofpearl of an abalone snail, a natural material from whose hardness and resilience we can still learn quite a bit. These exceptional mechanical properties have not yet been exceeded by man-made materials. Why? Because until recently nobody understood, how the snails do it. But now that clever minds have solved the mystery, that problem is out of the way. And so in the not so far away future it just might be that some materials scientists will be able to get rid of the annoying habit of ceramics to be so very brittle. Speaking of mother nature's wonders in creating materials, our teeth are another great example. Here, the strength lies, contradictorily, in its many defects that make sure that we can chew all those remaining unhealthy Christmas cookies. Aside from New Year's resolutions, this is a great thing and is currently being investigated further at Michigan Technological University.

Now in 2020, all developments concerning $\mathrm{CO}_{2}$-neutral energy supply are still and expected to be even more so research topics of highest priority. That is why we are very pleased that ceramics are one of the big players providing properties no other material can. In solar cell technology for example, ceramics can be used to create virtually any compound to manufacture solar cells with the highest robustness and long-term durability. All this is great, but even more interesting would be a material that could turn almost any surface into a solar power plant. That is also what scientists at the Karlsruhe Institute of Technology (KIT) thought and initiated a major new research project. Their objective: the development of ceramic solar cells that can be applied in liquid form.

Exciting times have also begun for the space industry. New space is called the disruption of a market previously dominated by government organizations that is now enriched by many new ideas on how to produce smaller, more compact and lighter-weighted systems. Learn more in this issue about the broad variety of ceramic materials that can help achieve these endeavors!

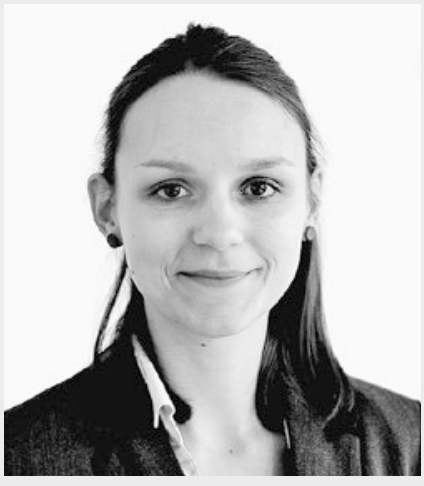

Leyla Buchholz Responsible Editor leyla.buchholz@springernature.com

\section{Access to the E-Magazine}

If you already are a subscriber to the Interceram, you can activate the Journal Archive and read the E-Magazine under www.springerprofessional.de/ en/register by using your customer number. 